\title{
O TRATAMENTO DE EMERGÊNCIA E A VISÃO DO STJ SOBRE A DISPENSA DO PRAZO DE CARÊNCIA PELOS PLANOS DE SAÚDE
}

\section{THE EMERGENCY TREATMENT AND THE STJ'S VISION ON THE WAIVER OF GRACE FOR THE HEALTH CARE PLANS}

\author{
${ }^{1}$ Eduardo Cambi \\ ${ }^{2}$ Mateus Vargas Fogaça
}

\section{RESUMO}

O objetivo do presente estudo é compreender as regras relativas aos prazos de carência dos planos de saúde privada no Brasil e a necessidade de sua dispensa para o caso de tratamentos emergenciais. Analisa o direito à saúde como direito fundamental social, destacando o tratamento a ele conferido pela Constituição Federal de 1988. Aborda a alteração do perfil da autonomia privada como decorrência da constitucionalização do direito civil e a sua submissão aos direitos fundamentais. Por fim, contextualiza as decisões do Superior Tribunal de Justiça e demonstrar a ilegalidade da Resolução ${ }^{\circ} 13$ do Conselho de Saúde Suplementar.

Palavras-Chave: Direito à saúde; Planos de saúde; Tratamento emergente; Prazo de carência; Lei ${ }^{\circ} 9.656 / 98$.

\section{ABSTRACT}

The aim of this study is to understand the rules on waiting periods of private health care in Brazil and the need for their dismissal in case of emergency treatments. It analyzes the right to health as a fundamental social right, highlighting the treatment given to it by the Federal Constitution of 1988. Addresses the changing profile of private autonomy as a result of the constitutionalization of civil law and its submission to fundamental rights. Finally, contextualize the decisions of the

\footnotetext{
1 Professor da Universidade Estadual do Norte do Paraná - UENP, (Brasil). E da Universidade Paranaense UNIPAR, (Brasil). E-mail: eduardocambi@hotmail.com

${ }^{2}$ Mestre em Ciência Jurídica pela Universidade Estadual do Norte do Paraná - UENP, (Brasil). Especialista em Direito Imobiliário pela Universidade Positivo. Pesquisador do Grupo de Estudos Neoconstitucionalismo e Neoprocessualismo (UENP). Advogado. E-mail: mavafo@hotmail.com
} 
High Court of Justice to demonstrate the illegality of Resolution No. 13 of the Council of Supplementary Health.

Keywords: Right to health; Health plans; Treatment emergent; Grace period; Law n ${ }^{\circ}$ 9,656/98.

SUMÁRIO: 1. Introdução; 2. A saúde como um direito fundamental social no Brasil; 3. A submissão da autonomia privada aos direitos fundamentais; 4. O prazo de carência para a cobertura dos planos de saúde; 5 . As decisões do Superior Tribunal de Justiça sobre o tema após a entrada em vigor da Lei n ${ }^{\circ}$ 9.656/98; 6. Considerações finais; 7. Referências.

\section{INTRODUÇÃO}

A história constitucional brasileira demonstra que a saúde normalmente foi tratada de modo superficial pelas diversas Constituições que existiram, a ponto de se dizer que a atual ordem constitucional rompeu paradigmas quanto ao tema.

A saúde foi enfatizada pelo constituinte de 1988, sendo alçada à condição de direito fundamental social, verdadeira cláusula pétrea, protegida contra a extinção ou rebaixamento pelo Constituinte derivado.

Como direito de todos e dever do Estado (art. 196), ao lado do serviço público de saúde e mediante regulamentação, fiscalização e controle do Poder Público (art. 197), a Constituição de 1988 (CF/88) autorizou expressamente a exploração econômica da saúde pela iniciativa privada (art. 199), que também poderá participar de forma complementar do sistema único de saúde, segundo diretrizes deste, mediante contrato de direito público ou convênio, concedendo-se preferência às entidades filantrópicas e às sem fins lucrativos.

A regulamentação da saúde suplementar, no entanto, ocorreu somente uma década depois, com a edição da Lei $\mathrm{n}^{\circ}$ 9.656/98, que tratou dos planos e seguros de assistência à saúde e criou o Conselho de Saúde Suplementar (CONSU) com competência para, dentre outros assuntos, estabelecer e supervisionar a execução de políticas e diretrizes gerais do setor de saúde suplementar. Posteriormente, a Lei no 9.961/00 criou a Agência Nacional de Saúde Suplementar (ANS), autarquia sob o regime especial, vinculada ao Ministério da Saúde, como órgão de regulação, normatização, controle e fiscalização das atividades que garantam a assistência suplementar à saúde. 
Antes disso, no entanto, mesmo que à margem de regulamentação estatal, por mais de trinta anos a iniciativa privada patrocinou diversas medidas de proteção à saúde, desenvolvendo serviços de assistência médica no âmbito empresarial, voltados à saúde dos trabalhadores (SILVEIRA, 2009, p. 59).

No entanto, apesar de decorridas quase duas décadas da regulamentação da saúde suplementar no Brasil, o aparente conflito existente entre a Lei $n^{\circ}$ 9.656/98 e a Resolução $n^{\circ}$ 13/98, do Conselho de Saúde Suplementar, mantém atual a discussão a respeito da necessidade de se dispensar o prazo de carência nos contratos de plano de saúde para tratamento emergente, à luz do entendimento do Superior Tribunal de Justiça.

Nesse pano de fundo, embasado em pesquisa bibliográfica e jurisprudencial sobre o tema e adotando o método dedutivo, o presente estudo buscará demonstrar a inaplicabilidade da Resolução $n^{\circ} 13 / 98$ do CONSU, no que se refere ao prazo de carência para tratamentos de emergência.

\section{A SAÚDE COMO UM DIREITO FUNDAMENTAL SOCIAL NO BRASIL}

As diversas transformações pelas quais a sociedade passou entre a metade final do Século XIX e o início do Século XX, quando o fundamento liberal-individualista dos direitos fundamentais passa a não atender satisfatoriamente às demandas da justiça social, ampliou-se a intervenção do Estado em diversos setores, inclusive na economia e na autonomia privada, implantando uma nova forma de interpretação da liberdade negocial e da igualdade formal até então imperantes.

Já não era mais adequado compreender o indivíduo como um ser isolado da sociedade em que vivia. Passou-se a entender necessária uma análise mais abrangente das coisas, para se compreender o indivíduo no contexto social em que estiver inserido, ciente de sua ânsia por tratamento específico, conforme sua posição na sociedade (AGRA, 2010, p. 523).

A transformação do pensamento mostrou a necessidade de avanço na concepção dos direitos fundamentais de primeira dimensão, que então passaram a conviver com os de segunda dimensão. Esse avanço deu origem aos direitos fundamentais sociais, calcados no princípio da diferença, visando a salvaguardar os indivíduos sem plenas condições de exercitarem plenamente 
seus direitos mais básicos, devido à hipossuficiência econômica, educacional ou cultural (CAMBI; LIMA, 2015, p. 179).

Tais direitos fundamentais partem da concepção segundo a qual a falta de atendimento às necessidades de cada pessoa redunda em efeitos negativos a toda a sociedade, ao passo que o suprimento das carências individuais teria o condão de produzir efeitos positivos sobre aquela mesma sociedade (MALISKA, 2001, p. 58). Assim, estando voltados aos mais carentes, debilitados e excluídos da sociedade, os direitos fundamentais sociais possuem estrutura distinta dos direitos de liberdade e igualdade, por exigirem ações positivas do Estado para a realização dos programas por eles veiculados (HESSE, 2001, p. 98), como acontece com consumidores, reconhecidamente vulneráveis em relação aos fornecedores (CDC, art. $4^{\circ}$, inciso I), bem como com os trabalhadores face aos empregadores (CAMBI, 2016, p. 54-60).

O direito fundamental à saúde está intimamente ligado ao também fundamental direito à vida, pois, a depender do dano causado à saúde do indivíduo, sua própria vida estará em perigo. Na seara infraconstitucional, a proteção à saúde é considerada um direito básico do consumidor (CDC, art. $5^{\circ}$, inciso I) em decorrência dessa forte ligação com o direito à vida (MIRAGEM, 2012, p. 197).

No entanto, a relação entre o direito à saúde e o direito à vida não se limita à proteção da vida, pois também alcança a promoção da qualidade de vida do cidadão, como aponta o preâmbulo da Constituição da Organização Mundial da Saúde (OMS, 1946, online): "A saúde é um estado de completo bem-estar físico, mental e social, e não consiste apenas na ausência de doença ou de enfermidade".

Como já reconheceu o Supremo Tribunal Federal no julgamento do AgR no RE 271.286 (Segunda Turma, Rel. Min. Celso de Mello, julgado em 12/09/00), a saúde constitui um direito público subjetivo, prerrogativa indisponível assegurada à totalidade dos indivíduos que se relaciona intimamente com a dignidade da pessoa humana.

Dotado de aplicabilidade imediata $\left(\mathrm{CF}\right.$, art. $\left.5^{\circ}, \S 1^{\circ}\right)$, o direito social à saúde deve ser efetivado com vistas à promoção do postulado da dignidade da pessoa humana (TRETTEL, 2010, p. 47). Enquanto direito fundamental, se descumpridos os seus preceitos, seja pela Administração Pública, seja pelo Poder Legislativo ou mesmo pela iniciativa privada, competirá ao Poder Judiciário promover a sua pronta efetivação (GRAU, 2005, p. 35). 
Com efeito, há uma interação de diversos fatores capazes de, coletivamente, proporcionar dignidade à pessoa humana, como sugere o art. $3^{\circ}$ da Lei Orgânica da Saúde (Lei n ${ }^{\circ}$ 8.080/90): "Os níveis de saúde expressam a organização social e econômica do País, tendo a saúde como determinantes e condicionantes, entre outros, a alimentação, a moradia, o saneamento básico, o meio ambiente, o trabalho, a renda, a educação, a atividade física, o transporte, o lazer e o acesso aos bens e serviços essenciais".

Os direitos fundamentais constituem um conjunto de normas destinado a proteger os bens jurídicos mais sensíveis na proteção da dignidade humana (SARLET, 2006, p 35-35). Com base no conteúdo de cada um, os direitos fundamentais podem ser classificados em seis grupos, $i$ ) direitos individuais (art. $5^{\circ}$ ), ii) direitos à nacionalidade (art. 12), iii) direitos políticos (arts. $14 \mathrm{a}$ 17), iv) direitos sociais (arts. $6^{\circ}, 193$ e seguintes), v) direitos coletivos (art. $5^{\circ}$ ) e vi) direitos solidários (arts. $3^{\circ}$ e 225) (SILVA, 2010, p. 183-184).

Em seu art. 6º a Constituição Federal de 1988 arrolou como direitos fundamentais sociais a educação, a saúde, a alimentação, o trabalho, a moradia, o lazer, a segurança, a previdência social, a proteção à maternidade e à infância e a assistência aos desamparados.

$\mathrm{Na}$ estrutura dos direitos fundamentais apresentada pela $\mathrm{CF} / 88$, o direito à saúde integra os direitos sociais, ou direitos fundamentais de segunda dimensão, em clara demonstração da nova postura adotada pelo Estado brasileiro, de abandono do posto de mero garantidor de direitos individuais para ocupar a posição de fornecedor de prestações positivas, tendentes a saciar as necessidades básicas do cidadão (MAPELLI; COIMBRA; MATOS, 2012, p. 15).

Por isso, ao direito à saúde coube ocupar espaço no Título destinado à Ordem Social, objetivando ao bem-estar e a justiça social. Independentemente de ser executada pelo Poder Público ou pela iniciativa privada, compete ao Estado a realização de prestações positivas em seu favor, formulando políticas públicas sociais e econômicas tendentes a sua promoção, proteção e recuperação da saúde (MARTINS; DIMOULIS, 2010, passim).

\section{A SUBMISSÃO DA AUTONOMIA PRIVADA AOS DIREITOS FUNDAMENTAIS}

Ao contrário de diversas Constituições brasileiras, muitas das quais não dedicaram sequer uma regra ao direito à saúde, além de inseri-lo no rol de direitos fundamentais, mantendo 
sob o domínio do Poder Público a regulamentação, fiscalização e o controle das ações e serviços de saúde, o art. 199 da Constituição Federal de 1988 liberou acesso à iniciativa privada para a exploração da assistência à saúde (OTERO; MASSARUTTI, 2015, p. 129-130).

Sobre a atuação da iniciativa privada na assistência à saúde, a CF/88 prevê duas situações. Na primeira, autoriza-se as instituições privadas a atuar de forma complementar ao sistema único de saúde (SUS), mediante contrato de direito público ou convênio, concedendo-se preferência às entidades filantrópicas e às sem fins lucrativos. A segunda hipótese, objeto do presente estudo, refere-se à assistência à saúde por meio da iniciativa privada, alheia às regras do SUS.

Ao autorizar a exploração econômica da assistência à saúde pela iniciativa privada, admitiu-se a possibilidade de se exercer a autonomia privada com o objetivo de se firmar contratos destinados à prestação desse tipo de serviço.

Ao inaugurar uma ordem econômica neoliberal, baseada na livre iniciativa e defesa do consumidor, dentre outros, a $\mathrm{CF} / 88$ aparentemente contradiz a postura intervencionista exigida para a efetivação dos direitos fundamentais por ela positivados. No entanto, como se deve buscar a harmonização das regras e dos princípios constitucionais, impõe-se uma interpretação conciliadora para as disposições aparentemente confrontantes.

No que se refere à assistência à saúde executada por instituições particulares, justamente por se relacionar a um direito fundamental social, a autonomia privada deve se submeter às balizas impostas pela própria $\mathrm{CF} / 88$, dentre as quais se encontra a intervenção estatal destinada a dar cumprimento aos fundamentos da República, em especial, o da dignidade da pessoa humana.

A limitação do poder econômico pela ordem jurídica implementada pelo Estado do Bem-Estar Social, com a aplicação de princípios constitucionais a institutos jurídicos privatísticos, como o contrato e a propriedade, visou à proteção das pessoas mais vulneráveis da sociedade, como é o caso do consumidor idoso e enfermo, apontados como hipervulneráveis ou com vulnerabilidade agravada (MARQUES, 2012, p. 41).

A publicização do direito privado causou a submissão do poder econômico aos direitos fundamentais, que devem ser respeitados. Assim, a clássica concepção da autonomia da vontade e da obrigatoriedade dos contratos nas relações privadas já não encontra espaço na ordem constitucional atual (CAMBI; FOGAÇA, 2015, p. 25). Exemplificativamente, é o que se verifica 
com a limitação da vontade de contratar a princípios gerais, limitadores da liberdade das partes de contratar, como é o caso do art. 421 do Código Civil, que prevê a submissão da liberdade de contratar à função social do contrato.

A Constituição Federal de 1988 introduziu uma forma heterogênea de proteção da autonomia privada. Ela obterá tutela jurídica reforçada quando se trata de liberdade nas escolhas existenciais, como ocorre nas questões atinentes à disposição sobre consentimento para tratamento médico, e proteção flexibilizada quando se referir ao âmbito patrimonial, em razão de a atividade econômica almejar objetivos que não se encerram em si mesmos (SARMENTO, 2006, p. 177-178).

O projeto de sociedade brasileira ainda em construção visa a valorizar a dignidade da pessoa humana no maior número possível de esferas, nas quais os negócios privados estão inseridos, dada a possibilidade de violação dos direitos fundamentais pela supremacia econômica entre os contratantes. É daí que decorre a necessidade de a autonomia privada ser submetida aos demais valores fundantes do Estado brasileiro (CAMBI; LIMA, 2015, p. 187).

A atividade econômica não pode ser considerada um fim em si mesmo. Logo, sendo livre para executar a assistência à saúde, a iniciativa privada pode ou não explorar essa atividade. Contudo, tendo optado por exercer essa prática comercial, deverá subordinar sua conduta às limitações da ordem jurídica (PRATA, 1982, p. 199).

Como decidiu já o Supremo Tribunal Federal (RE 201.819, Segunda Turma, Rel. Min. Gilmar Mendes, julgado em 11/10/2005), a autonomia da vontade jamais autorizará que o particular possa transgredir ou ignorar as limitações da ordem jurídica constitucional, dada a incidência da eficácia e da força normativa que os direitos fundamentais exercem sobre as relações privadas.

Portanto, tratando-se de tema relevante ao direito constitucional, a assistência à saúde terá prioridade de tratamento em face da autonomia privada, cujo exercício não pode ocorrer em prejuízo ou com desrespeito aos direitos e garantias alheias, notadamente aqueles estipulados constitucionalmente.

\section{O PRAZO DE CARÊNCIA PARA A COBERTURA DOS PLANOS DE SAÚDE}


A relação jurídica mantida entre o particular e as empresas de plano de saúde é tipicamente de consumo, haja vista a possibilidade de serem identificados nela todos os elementos necessários para tanto. Com efeito, são tipicamente fornecedoras as empresas que, mediante remuneração, prestam serviços de saúde. Embora condicionado a evento futuro, ao plano de saúde contratado corresponde uma contraprestação pecuniária. Além disso, o contratante e seus dependentes adquirem ou utilizam os serviços de saúde, como destinatários finais, sendo inegavelmente consumidores (GREGORI, 2011, p. 131-132).

É questão ultrapassada a submissão dos contratos de plano de saúde às normas do Código de Defesa do Consumidor (CDC), em paralelo à própria Lei $\mathrm{n}^{\circ}$ 9.656/98, desde que o Superior Tribunal de Justiça editou a Súmula no 469, assim redigida: "Aplica-se o Código de Defesa do Consumidor aos contratos de plano de saúde". Essa posição é inteiramente justificada pela necessidade de o Estado promover a defesa do consumidor, consoante prevê o art. $5^{\circ}$, inciso XXXII, da Constituição Federal.

Já que a defesa do consumidor também é um princípio da Ordem Econômica (CF, art. 170, inciso V) o Estado impõe limites ao poder econômico dos fornecedores e busca a equilibrar as partes desiguais, por meio dos instrumentos apresentados pelo CDC e demais leis esparsas, como é o caso da própria Lei ${ }^{\circ} 9.656 / 98$, cujos dispositivos preveem coberturas mínimas a serem oferecidas pelas operadoras de planos de saúde a seus consumidores (OTERO; MASSARUTTI, 2015, p. 136).

Da incidência do CDC aos contratos de plano de saúde, decorre a importante consideração de que as partes deverão observar a boa-fé na formação e na execução do contrato, inclusive com o cumprimento rigoroso dos deveres de informação, cooperação e lealdade, previstos nos arts. $6^{\circ}$, III, e 46, daquele Código (CAMBI; LIMA, 2015, p. 186).

Ademais, segundo o art. 54 e $\S$ do CDC, é indispensável a clareza e precisão das informações, que precisam ser assimilados pelo consumidor, com destaque para as cláusulas limitadoras de direitos, objetivando à fácil e imediata compreensão dos contratos, tipicamente de adesão (THOMAZ, 2009, p. 128).

A intervenção do Estado promovida com fundamento no direito fundamental à saúde na autonomia da vontade incide, pois, direta e cogentemente nos contratos de plano de saúde. Visa a salvaguardar a vida do consumidor, o que tem justificado o afastamento das cláusulas de carência 
invocadas pelas empresas de planos de saúde com o objetivo de se negarem a prestar tratamentos emergentes aos pacientes (NUNES JÚNIOR, 2009, p. 161).

Dispondo sobre os planos e seguros privados de assistência à saúde no Brasil, a Lei ${ }^{\circ}$ 9.656/98 define em seu art. 12, inciso V, que o prazo máximo de carência para cobertura dos casos de urgência e emergência será de 24 (vinte e quatro) horas.

Por sua vez, o art. 35-C da mesma Lei determina a obrigatoriedade da cobertura em casos de emergência, assim considerados os que implicarem risco imediato de vida ou de lesões irreparáveis para o paciente, caracterizado em declaração do médico assistente, bem como nos casos de urgência, assim entendidos os resultantes de acidentes pessoais ou de complicações no processo gestacional, e os casos de planejamento familiar.

A respeito da relevante diferenciação entre os casos de urgência e emergência, confiramse as lições de BOTTESINI e MACHADO (2005, p. 316):

\begin{abstract}
Indispensável esclarecer que não se confundem a emergência e a urgência. É provável que a confusão ordinariamente vista entre elas decorra do fato de serem sinônimas as expressões e de ambas implicarem risco para a vida ou para a integridade física de uma pessoa. A urgência traz consigo a ideia daquilo que deve ser feito com rapidez, imediatamente, enquanto a emergência traz a ideia de imprevisto, de perigoso e de fortuito, embora não necessite de ser atendida com rapidez, imediatamente. [...] $A$ emergência, por outro lado, exige providências de outros profissionais aos quais o doente seja apresentado, para que seja providenciado o atendimento por médico ou por outro profissional adequado ao caso, tão rápido quanto necessário, afastada a ideia de imediatidade que emerge com a urgência. (grifo nosso)
\end{abstract}

Com esse regramento legal, fica suficientemente claro que, estando o consumidor em estado de urgência ou emergência, será obrigatória a cobertura total e ilimitada do tratamento médico pelo plano de saúde, até cessar aquele estado, desde que cumprida a carência mínima de 24 (vinte e quatro) horas, contadas da contratação.

No entanto, dois meses após a entrada em vigor da Lei no 9.656/98, em 04/11/1998, o Conselho de Saúde Suplementar (CONSU) publicou a Resolução no 13/98 e, desde então, as operadoras de plano de saúde têm se embasado nela para limitar os tratamentos de emergência no período de carência às 12 (doze) primeiras horas de atendimento para, dali em diante, transferirem a responsabilidade e o custeio ao próprio paciente. 
Isso ocorre porque a Resolução ${ }^{\circ}$ 13/98 do CONSU, relativa aos contratos de plano ou seguro hospitalar, dispõe que o atendimento de urgência relativo a acidentes pessoais será garantido, sem restrições, depois de 24 (vinte e quatro) horas da vigência do contrato (art. $3^{\circ}$, § $\left.2^{\circ}\right)$. No entanto, a referida resolução estipula que o atendimento de urgência realizado durante o prazo de carência (180 dias, conforme art. 12, inciso V, da Lei $n^{\circ}$ 9.656/98) abrangerá a mesma cobertura prevista para o plano ou seguro ambulatorial, sem garantia de cobertura para internação $\left(\operatorname{art.} 3^{\circ}, \S 1^{\circ}\right)$.

Ao fazer referência à cobertura para o plano ou seguro ambulatorial, a Resolução $\mathrm{n}^{\circ}$ 13/98 do CONSU faz remissão ao seu art. $2^{\circ}$ - "o plano ambulatorial deverá garantir cobertura de urgência e emergência, limitada até as primeiras 12 (doze) horas do atendimento" -, relativo ao plano ambulatorial, cuja cobertura é limitada às 12 (doze) primeiras horas de atendimento, sendo de responsabilidade do paciente o custeio da continuidade do tratamento, caso necessário.

Adotando semelhante postura, as operadoras de planos de saúde acabaram por infringir o postulado da boa-fé contratual que deve ser observado nas relações de consumo. Deve ser considerada abusiva a prática comercial que limita o atendimento de casos de emergência a apenas 12 (doze) horas, pois a restrição da obrigação da fornecedora inerente ao contrato ameaça o equilíbrio contratual e coloca o consumidor em posição exageradamente desvantajosa, o que é vedado pelo CDC (art. 51, inciso IV e $\S 1^{\circ}$, inciso II).

Além disso, sendo impossível a utilização do serviço de atendimento à saúde contratado, ele torna-se impróprio para o fim ao qual se destina (CDC, art. 18, $\S 6^{\circ}$, inciso III e art. $20, \S 2^{\circ}$ ), desvirtuando-se a própria natureza do contrato, pois o fornecedor limita demasiadamente sua responsabilidade, impingindo-a injustamente ao consumidor, que razoavelmente espera poder usufruir da cobertura contratada em caso de emergência, possuindo a expectativa de encontrar assistência para a integral cura da doença que lhe acometeu (MARQUES; LOPES; PFEIFFER, 1999, p. 81).

Deve ser acrescido que a negativa de atendimento de emergência durante o período de carência, por prazo superior a 12 (doze) horas, é indevida, porque se baseia na Resolução $\mathrm{n}^{\circ}$ 13/98 do CONSU, a quem não foi atribuída competência para restringir a prestação de serviço das operadoras de planos de saúde. 
Com efeito, a Medida Provisória ${ }^{\circ}$ 2.177-44/2001 introduziu o art. 35-A à Lei $n^{\circ}$ 9.656/98, para criar o Conselho de Saúde Suplementar, atribuindo-lhe competência, dentre outras coisas, para estabelecer e supervisionar a execução de políticas e diretrizes gerais do setor de saúde suplementar.

Pode-se perceber que o CONSU, enquanto órgão do Poder Executivo, fez mais que estabelecer e supervisionar o setor de saúde suplementar ao criar o art. $3^{\circ}$ e $\S \S$ da Resolução no 13/98. Ele excedeu seu poder regulamentar e, por consequência, restringiu direito previsto em diploma legal que the é hierarquicamente superior.

Ora, uma norma regulamentadora jamais poderia ultrapassar a barreira daquilo que a norma regulamentanda the impôs. Também não há possibilidade de o regulamento da lei estabelecer aquilo que a lei não prevê, tampouco tratar daquilo que ela própria já estipulou, como é o caso dos prazos de carência fixados pela Lei $n^{\circ}$ 9.656/98, como assentou recentemente o Tribunal de Justiça do Estado de São Paulo, ao julgar a Apelação Cível $\mathrm{n}^{\circ}$ 101352714.2014.8.26.0001 (5 $5^{\mathrm{a}}$ Câmara de Direito Privado, Rel. Des. Mônaco da Silva, julgado em 31/08/2016).

O que é mais despropositado e ilegal é, ainda, a própria extinção de direitos previstos na lei, como no caso, em que são excluídas, pela Resolução no 13/98 do CONSU, hipóteses de tratamentos emergenciais, em prejuízo do próprio direito à saúde, como registrou o Superior Tribunal de Justiça, REsp 962.980/SP (4 Turma, Rel. Min. Luis Felipe Salomão, julgado em 13/03/2012).

Sobre o tema, a Súmula n 103 do Tribunal de Justiça do Estado de São Paulo é incisiva ao afastar a aplicação da Resolução 13/98 do CONSU, por considerar "É abusiva a negativa de cobertura em atendimento de urgência elou emergência a pretexto de que está em curso período de carência que não seja o prazo de 24 horas estabelecido na Lei n. 9.656/98".

Desse modo, não encontrando respaldo no ordenamento jurídico nacional, resulta inaplicável a Resolução no 13/98 do CONSU. Portanto, é descabida a negativa de cobertura de tratamento emergente, às 12 (doze) primeiras horas de atendimento, impondo-se a prevalência da regra de apenas 24 (vinte e quatro) horas de carência para tal espécie de cobertura. 


\section{AS DECISÕES DO SUPERIOR TRIBUNAL DE JUSTIÇA SOBRE O TEMA APÓS A ENTRADA EM VIGOR DA LEI N 9.656/98}

O direito fundamental à saúde é imprescindível à vida com dignidade do cidadão. Apesar disso, é crescente a necessidade de judicialização do tema, face à reiterada dificuldade enfrentada pelos usuários da saúde pública e privada no Brasil (FACHIN; FOGAÇA, 2014, p. 49), como é o caso dos consumidores cujo tratamento emergencial é obstado pelas operadoras de planos de saúde.

Essa crescente judicialização do direito à saúde, também decorrente da massificação dos conflitos da sociedade moderna, torna importante a análise sistemática das decisões que vêm sendo proferidas pelo Superior Tribunal de Justiça a respeito do tema objeto da presente investigação.

Nesse sentido, utilizando-se o sistema de pesquisa jurisprudencial disponibilizado na página do STJ, foi realizada busca pelas palavras chaves "carência e plano e saúde", pelo período compreendido entre 04/09/1998 e 14/09/2016. Foram desconsideradas, dessa forma, as decisões proferidas antes da entrada em vigor da Lei $n^{\circ}$ 9.656/98, já que no período anterior não vigorava regramento legal semelhante ao atual.

Do universo de 64 (sessenta e quatro) acórdãos nos quais houve referência às palavraschave sugeridas, foi imperativa a exclusão de 40 (quarenta) julgados ${ }^{3}$, nos quais o mérito do recurso não tratava da dispensa da carência do plano de saúde para o tratamento emergencial do consumidor, ou, quando ventilado o tema, as partes o fizeram para subsidiar outras teses, como o da ocorrência de danos morais em razão da negativa de atendimento ou o da ocorrência de doenças preexistentes à contratação, por exemplo.

3 São eles: AgInt no AREsp 892.340/SP; AgInt no AREsp 858.013/DF; REsp 1592278/DF; AgRg no AREsp 854.954/CE; AgRg no Ag 845.103/SP; REsp 1471569/RJ; AgRg no REsp 1432505/DF; AgRg no AREsp 672.242/DF; AgRg no REsp 1301763/DF; REsp 1243632/RS; AgRg no AREsp 592.855/SP; AgRg no AREsp 473.914/PR; AgRg no AREsp 454.610/RN; AgRg no AREsp 144.418/MT; AgRg no AREsp 478.831/SP; AgRg no REsp 1386759/RJ; AgRg no AREsp 110.818/RS; AgRg no AREsp 125.658/SP; AgRg no AREsp 327.767/CE; AgRg no AREsp 213.169/RS; HC 207.907/PE; REsp 980.326/RN; REsp 865.489/RS; AgRg no Ag 1322204/PA; MS 13.967/DF; REsp 285.618/SP; RMS 22.362/RJ; REsp 313.914/SP; AgRg na MC 11.805/RJ; EDcl no REsp 795.917/RJ; REsp 795.917/RJ; REsp 657.717/RJ; REsp 259.263/SP; REsp 531.281/SP; REsp 356.026/MA; REsp 588.536/RJ; REsp 402.727/SP; AgRg no Ag 455.006/SP; REsp 264.060/PI; MS 3.384/DF. 
Do mesmo modo, outros 20 (vinte) acórdãos ${ }^{4}$, mesmo versando sobre a dispensa da carência para atendimentos emergenciais, também foram excluídos da análise devido à falta de apreciação direta do tema pelo STJ, por deficiência da fundamentação do recurso, necessidade de reexame de provas ou porque, estando o recurso fundado na divergência, a orientação do tribunal se firmou no mesmo sentido da decisão recorrida, exemplificativamente.

Feita essa filtragem inicial, constatou-se terem remanescido apenas 04 (quatro) acórdãos nos quais se realizou a análise aprofundada da matéria, nessas quase duas décadas de vigência da Lei no 9.656/98, equivalendo à média de uma decisão a cada quatro anos e meio decorridos.

O REsp 222.339/PB (4 $4^{\mathrm{a}}$ Turma, Rel. Ministro Ruy Rosado de Aguiar, julgado em 28/06/2001, DJ 12/11/2001, p. 155) foi a primeira decisão onde o Superior Tribunal de Justiça teve oportunidade de abordar o assunto. Tratava-se de paciente que buscava o pagamento das despesas médicas decorrentes de acidente de trânsito sofrido durante o prazo de carência. Ele havia obtido êxito no juízo de origem, mas a sentença foi reformada pelo Tribunal de Justiça da Paraíba, que julgou improcedente o pedido. A sentença restabelecida pelo STJ, por unanimidade, fez prevalecer o argumento de que a situação emergencial do paciente constitui justo motivo para o afastamento do prazo carencial, sendo devida a cobertura do plano de saúde. A ementa foi assim redigida: "PLANO DE SAÚDE. Prazo de carência. Internação de urgência. O prazo de carência não prevalece quando se trata de internação de urgência, provocada por fato imprevisível causado por acidente de trânsito. Recurso conhecido e provido".

O STJ analisou a matéria pela segunda vez apenas em 17/12/2007, quando do julgamento do REsp 466.667/SP (4a Turma, Rel. Min. Aldir Passarinho Júnior, DJ 17/12/2007, p. 174). Nesse caso, a paciente foi acometida de tumor neurológico, com comprometimento da medula espinhal. Considerando válida a estipulação de cláusula de carência nos contratos de plano de saúde, a regra foi temperada devido à necessidade de atendimento de urgência, para tratamento de doença grave que acometeu a paciente, com expressa referência ao REsp

4 São os seguintes: AgInt no AREsp 875.371/RS; AgRg no AREsp 774.733/DF; AgRg no AREsp 812.432/GO; AgRg no REsp 1503003/SP; AgRg no AREsp 624.092/SP; AgRg no AREsp 627.782/SP; AgRg no AREsp 520.750/SP; AgRg no AREsp 595.365/SP; AgRg no AREsp n. 320.484/PA; AgRg no AREsp 570.044/PE; AgRg no AREsp 474.625/MG; AgRg no AREsp 409.213/RJ; AgRg no AREsp 437.831/GO; AREsp 327.221/SP; AgRg no AREsp 320.484/PA; AgRg no REsp 1401390/MT; AgRg no REsp 929.893/PR; AgRg no Ag 132132'1/PR; AgRg no Ag 1393282/RS; REsp 300.138/SP. 
222.339/PB, com o que se deu parcial provimento ao recurso, à unanimidade, reformando-se acórdão do Tribunal de Justiça de São Paulo. Eis o teor da ementa:

CIVIL E PROCESSUAL. ACÓRDÃO ESTADUAL. NULIDADE NÃO CONFIGURADA. PLANO DE SAÚDE. CARÊNCIA. TRATAMENTO DE URGÊNCIA. RECUSA. ABUSIVIDADE. CDC, ART. 51, I. [...]. III. Lídima a cláusula de carência estabelecida em contrato voluntariamente aceito por aquele que ingressa em plano de saúde, merecendo temperamento, todavia, a sua aplicação quando se revela circunstância excepcional, constituída por necessidade de tratamento de urgência decorrente de doença grave que, se não combatida a tempo, tornará inócuo o fim maior do pacto celebrado, qual seja, o de assegurar eficiente amparo à saúde e à vida. IV. Recurso especial conhecido em parte e provido.

Na terceira oportunidade para análise, já em 03/05/2011, o STJ julgou por unanimidade o REsp 1.055.199/SP (3 ${ }^{\text {a }}$ Turma, Rel. Min. Sidnei Beneti, DJe 18/05/2011). Igualmente, afastou a cláusula de carência contratualmente estipulada, dada a ocorrência de situação emergencial, mostrando que a recusa de cobertura frustraria o próprio sentido do contrato de seguro, já que o paciente fora internado na UTI com suspeita de derrame, devido ao histórico de infarto devidamente comunicado quando da assinatura do contrato. Além de fundamentar a decisão na orientação já esposada quando do julgamento do REsp 222.339/PB, bem como do REsp 466.667/SP, também foi invocada a Súmula 302/STJ, segundo a qual "É abusiva a cláusula contratual de plano de saúde que limita no tempo a internação hospitalar do segurado”. A ementa é a seguinte:

DIREITO DO CONSUMIDOR. PLANO DE SAÚDE. PERÍODO DE CARÊNCIA. SITUAÇÕES EMERGENCIAIS GRAVES. NEGATIVA DE COBERTURA INDEVIDA. I - Na linha dos precedentes desta Corte, o período de carência contratualmente estipulado pelos planos de saúde, não prevalece, excepcionalmente, diante de situações emergenciais graves nas quais a recusa de cobertura possa frustrar o próprio sentido e razão de ser do negócio jurídico firmado. [...].

Julgado em 13/03/2012, o REsp 962.980/SP (4 ${ }^{\text {a }}$ Turma, Rel. Min. Luis Felipe Salomão, DJe 15/05/2012) retrata caso em que o paciente foi acometido de tumor cerebral, maligno, com quadro médico grave, sendo-lhe negado o atendimento emergencial devido a não ter cumprido o prazo de carência estipulado em contrato. $\mathrm{O}$ pedido inicial foi acolhido em primeira instância. $\mathrm{O}$ Tribunal de Justiça de São Paulo, por sua vez, reformou parcialmente a sentença para impor limitação ao período de cobertura às 12 (doze) primeiras horas de internação, fundado na 
Resolução no 13/98 do CONSU. Apontando a fundamentalidade do direito à integridade física e à saúde, que irradia efeitos para toda a ordem jurídica, e visa proteger à dignidade humana e alcançar a justiça social, o STJ reconheceu a submissão do contrato ao CDC e apontou como sendo de 24 (vinte e quatro) horas o prazo de carência para atendimentos de urgência e emergência, afastando a incidência da Resolução nº 13/98 do CONSU, por exceder os limites da mera regulamentação da Lei $n^{\circ}$ 9.656/98. A decisão de provimento do recurso não foi unânime apenar por conta da divergência aberta pelo Min. Raul Araújo, que não consentiu apenas quanto à fixação de multa pelo descumprimento da tutela antecipada. Confira-se a ementa:

\begin{abstract}
SEGURO DE SAÚDE. RECURSO ESPECIAL. APRECIAÇÃO ACERCA DE VIOLAÇÃO À RESOLUÇÃO. DESCABIMENTO. NATUREZA DA RELAÇÃO JURÍDICA. CONSUMO. PRAZO CONTRATUAL DE CARÊNCIA PARA COBERTURA SECURITÁRIA. POSSIBILIDADE. CONSUMIDOR QUE, MESES APÓS A ADESÃO DE SEU GENITOR AO CONTRATO DE SEGURO, VÊ-SE ACOMETIDO POR TUMOR CEREBRAL E HIDROCEFALIA AGUDA. ATENDIMENTO EMERGENCIAL. SITUAÇÃO-LIMITE EM QUE O BENEFICIÁRIO NECESSITA, COM PREMÊNCIA, DE PROCEDIMENTOS MÉDICOS-HOSPITALARES COBERTOS PELO SEGURO. INVOCAÇÃO DE CARÊNCIA. DESCABIMENTO, TENDO EM VISTA A EXPRESSA RESSALVA CONTIDA NO ARTIGO 12, V, ALÍNEA "C", DA LEI 9.656/98 E A NECESSIDADE DE SE TUTELAR O DIREITO FUNDAMENTAL À VIDA. [...].
\end{abstract}

A detida análise do conteúdo das decisões proferidas pelo Superior Tribunal de Justiça, ao longo de praticamente duas décadas de vigência da Lei no 9.656/98, permite concluir que, em todos os casos onde se buscou cobertura do plano de saúde para o custeio de tratamento emergencial, houve o afastamento da cláusula de carência contratualmente prevista.

Ademais, o STJ indicou que o CONSU excedeu seu poder meramente regulamentar ao editar a Resolução no 13/98, não sendo admitida a restrição ao direito do consumidor levado a cabo por aquela normativa. Concluiu, assim, pela aplicação do prazo máximo de 24 (vinte e quatro) horas de carência, contados da contratação, para a cobertura de tratamentos de urgência ou emergência, tal como prevê o art. 12, inciso V, alínea 'c', da Lei no 9.656/98.

A autoridade das decisões proferidas pelo STJ é bastante expressiva, a ponto de os acórdãos antes analisados terem sido referidos em quase que a totalidade das demais decisões nas quais o tema foi ventilada, o que raramente ocorre em nossa tradição jurídica e explica o fato de o afastamento da cláusula de carência ter ocorrido por unanimidade em todos os julgamentos. 


\section{CONSIDERAÇÕES FINAIS}

Realizada a análise do tratamento conferido ao direito à saúde pela ordem constitucional vigente, foi possível identificar sua elevação à condição de direito fundamental social, o que não ocorria no âmbito das Constituições anteriores.

Os planos de saúde, que já existiam há várias décadas no Brasil, mesmo sem a correlata regulamentação, ganharam maior visibilidade e confiabilidade quando o constituinte facultou a exploração da assistência à saúde pela iniciativa privada, o que foi melhor estabelecido quando da edição da Lei no 9.656/98.

Nesse ínterim, a paulatina constitucionalização do direito privado provocou uma alteração no perfil da autonomia privada, que cedeu espaço, no campo contratual, à eficácia horizontal dos direitos fundamentais, passando a interferir nas relações privadas para assegurar a efetivação desses direitos.

As normas protetivas do Código de Defesa do Consumidor, em paralelo, têm tornado o mercado de consumo mais humano e solidário, salvaguardando os interesses da parte mais fraca da relação jurídica contratual, reconhecidamente vulnerável, como é o caso do consumidor que necessita da cobertura de seus tratamentos médicos por parte dos planos de saúde.

Sob esse pano de fundo, foram analisadas as balizas legais relativas aos prazos de carência aplicáveis aos planos de saúde no país, sendo possível concluir-se que, para fins de tratamento de saúde urgente ou emergente, não se pode exigir lapso temporal maior que 24 (vinte e quatro) horas, contatos da contratação.

Assim, as disposições divergentes veiculadas pela Resolução no $13 / 98$ do CONSU contrariam expressamente a Lei $n^{\circ} 9.656 / 98$, que lhe é hierarquicamente superior no ordenamento jurídico, além de advir de órgão estatal não dotado de competência para a edição de atos dessa espécie, razão pela qual não se pode admitir a sua aplicação aos casos concretos.

Por fim, analisado o conjunto de decisões proferidas pelo Superior Tribunal de Justiça, após a entrada em vigor da Lei $n^{\circ}$ 9.656/98, foi possível identificar a existência de apenas 04 (quatro) decisões, nas quais o tema foi enfrentado de modo seguro e uníssono, no sentido de se dispensar o prazo de carência dos contratos de plano de saúde nos casos de tratamento urgente e 
O Tratamento De Emergência E A Visão Do Stj Sobre A Dispensa Do Prazo De Carência Pelos Planos De Saúde

emergente. Apesar da pequena quantidade de julgados, tais decisões servem de precedentes seguros sobre a matéria, que vinculam os juízes de primeira e segunda instância em todo o Brasil (arts. 489, § $1^{\circ}$, inc. VI, e 926 do CPC).

\section{REFERÊNCIAS}

AGRA, Walber de Moura. Direitos sociais. In: MARTINS, Ives Gandra da Silva; MENDES, Gilmar Ferreira; NASCIMENTO, Carlos Valder do (Coords.). Tratado de direito constitucional. v. 1. São Paulo: Saraiva, 2010.

BOTTESINI, Maury Ângelo; MACHADO, Mauro Conti. Lei dos planos e seguros de saúde: comentada artigo por artigo. 2. ed. São Paulo: Revista dos Tribunais, 2005.

BRASIL, Superior Tribunal de Justiça, $4^{a}$ Turma, REsp 962.980/SP. Relator: Min. Luis Felipe Salomão, julgado em 13/03/2012, DJe 15/05/2012.

;___ Quarta Turma, REsp 222.339/PB. Relator Min. Ruy Rosado de Aguiar, julgado em 28/06/2001, DJ 12/11/2001, p. 155.

; __ Quarta Turma, REsp 466.667/SP. Relator Min. Aldir Passarinho Junior, julgado em 27/11/2007, DJ 17/12/2007, p. 174.

; __ . Quarta Turma, REsp 962.980/SP. Relator Min. Luis Felipe Salomão, julgado em 13/03/2012, DJe 15/05/2012.

; __ Terceira Turma, REsp 1.055.199/SP. Relator Min. Sidnei Beneti, julgado em 03/05/2011, DJe 18/05/2011.

; Supremo Tribunal Federal. $2^{\mathrm{a}}$ Turma, AgR no RE 271.286. Relator: Min. Celso de Mello. Julgado em 12/09/2000, DJ 24/11/2000.

DJ 27/10/2006.

. $2^{\mathrm{a}}$ Turma, RE 201.819. Relator: Min. Gilmar Mendes. Julgado em 11/10/2005,

BRASIL; Tribunal de Justiça do Estado de São Paulo. $5^{\text {a }}$ Câmara de Direito Privado, Apelação Cível 1013527-14.2014.8.26.0001. Rel. Des. Mônaco da Silva. Julgado em 31/08/2016.

BRASIL, Tribunal de Justiça de São Paulo, $5^{\text {a }}$ Câmara de Direito Privado, Apelação 101352714.2014.8.26.0001, Rel. Des. Mônaco da Silva, julgado em 31/08/2016.

CAMBI, Eduardo. Neoconstitucionalismo e neoprocessualismo. Direitos fundamentais, políticas públicas e protagonismo judiciário. São Paulo: Almedina, 2016. 
CAMBI, Eduardo; FOGAÇA, Marcos Vargas. Direito civil constitucional. Revista de Direito Privado, n. 61, jan.-mar./2015.

; LIMA, Jairo Néia. Dispensa do prazo de carência nos contratos de plano de saúde para tratamento urgente - uma leitura a partir da horizontalidade dos direitos sociais. Revista de Direito do Consumidor, n. 98, mar.-abr./2015.

FACHIN, Jéssica; FOGAÇA, Mateus Vargas. Direito fundamental à saúde: posicionamento do Supremo Tribunal Federal e judicialização. In: AMARAL, Sérgio Tibiriçá; ALVES, Fernando Brito; COIMBRA, Mário. Hermenêutica constitucional. Jacarezinho/PR, UENP \& Instituto Ratio Juris, 2014.

GRAU, Eros Roberto. Ensaio e discurso sobre a interpretação/aplicação do direito. 3. ed. São Paulo: Malheiros, 2005.

GREGORI, Maria Stella. Planos de saúde: a ótica da proteção do consumidor. 3 ed. São Paulo: Revista dos Tribunais: São Paulo, 2011.

HESSE, Konrad. Significado de los derecho fundamentales. In: BENDA, Ernesto et al (Org.) Manual de derecho constitucional. 2. ed. Madrid: Marcial Pons, 2001.

MALISKA, Marcos Augusto. O direito à educação e a Constituição. Porto Alegre: Sergio Antonio Fabris Editor, 2001.

MAPELLI JR, Reynaldo; COIMBRA, Mario; MATOS, Yolanda Alves Pinto Serrano de. Direito sanitário. São Paulo: Ministério Público/Imprensa Oficial, 2012.

MARTINS, Leonardo; DIMOULIS, Dimitri. Teoria geral dos direitos fundamentais. 2. ed. São Paulo: Revista dos Tribunais, 2010.

MARQUES, Claudia Lima (Coord.). Diálogo das Fontes: do conflito à coordenação de normas do direito brasileiro. São Paulo: Revista dos Tribunais, 2012.

; LOPES, José Reinaldo de Lima; PFEIFFER, Roberto Augusto Castellanos (Coords.). Saúde e Responsabilidade: seguros e planos de assistência privada à saúde. São Paulo: Revista dos Tribunais, 1999.

MIRAGEM, Bruno. Curso de direito do consumidor. 5 ed. São Paulo: Revista dos Tribunais, 2014.

NUNES JUNIOR, Vidal Serrano. A cidadania social na Constituição de 1988. São Paulo: Verbatim, 2009. 
ORGANIZAÇÃO MUNDIAL DA SAÚDE (OMS). Constituição da Organização Mundial da Saúde. 1946. Disponível em: <http://www.direitoshumanos.usp.br/index.php/OMSOrganiza\%C3\%A7\%C3\%A3o-Mundial-da-Sa\%C3\%BAde/constituicao-da-organizacaomundial-da-saude-omswho.html>. Acesso em: 11 set. 2016.

OTERO, Cleber Sanfelici; MASSARUTTI, Eduardo Augusto de Souza. A violação do direito à saúde pelas empresas de planos de saúde ao engarem eventos médicos não revistos no rol de procedimentos elaborado pela Agência Nacional de Saúde Suplementar brasileira. In: GABRICH, Frederico de Andrade; SILVA, Rogerio Luiz Nery da. Autonomia privada, regulação e estratégia. Florianópolis: Conpedi, 2015.

PRATA, Ana. A tutela constitucional da autonomia privada. Coimbra: Almedina, 1982.

SARLET, Ingo Wolfgang. A eficácia dos direitos fundamentais. 6. ed., Porto Alegre: Livraria do Advogado, 2006.

SARMENTO, Daniel. Direitos fundamentais e relações privadas. 2. ed. Rio de Janeiro: Lúmen Juris, 2006.

SILVA, José Afonso da. Curso de direito constitucional. 33. ed. São Paulo: Malheiros, 2010.

SILVEIRA, Karyna Rocha Mendes da. Doença preexistente nos planos de saúde. São Paulo: Saraiva, 2009.

THOMAZ, Afrânio Carlos Moreira. Lições de direito do consumidor. Rio de Janeiro: Lúmen Juris, 2009.

TRETTEL, Daniela Batalha. Planos de saúde na visão do STJ e STF. São Paulo: Verbatim, 2010. 